\title{
KARAKTERISITIK SIFAT FISIKOKIMIA TEH HERBAL "SEKAM" (SERAI KOMBINASI KAYU MANIS) SEBAGAI MINUMAN FUNGSIONAL
}

\author{
Desi Arisanti ${ }^{1)}$, Arif Murtaqi Akhmad Mutsyahidan ${ }^{2)}$ \\ ${ }^{1,2}$ Program Studi Teknologi Hasil Pertanian, Politeknik Gorontalo \\ Email: desiarisanti47@gmail.com ${ }^{1)}$
}

\begin{abstract}
ABSTRAK
Pemanfaatan serai dan kayu manis sebagai teh sangat bermanfaat bagi kesehatan. Serai dan kayu manis memiliki kandungan senyawa fungsional yang bermanfaat. Tujuan dari penelitian ini adalah: 1) .Untuk mengetahui kandungan fisikokimia teh herbal serai-kayu manis yang berupa kadar flavonoid, kadar abu, kadar air dan kadar vitamin C. 2). Bagaimana tingkat kesukaan panelis terhadap herbal serai-kayu manis.

Hasil penelitian menunjukkan bahwa tingkat kombinasi yang sesuai adalah T2 (warna, aroma) dan T3 (rasa). Adapun hasil analisis sifat kimia dengan penambahan kayu manis yaitu; kadar udara 6,08\% (T2), kadar abu 5,84\% (T2), kadar flavonoid (T1), dan kadar vitamin C 15,00\% (T3). Tingkat kesukaan panelis terbaik yang dihasilkan dari 3 atribut (warna, aroma, dan rasa) adalah perlakuan T2 (daun serai 1,5 g dan kayu manis 0,2 g). Dan dari data hasil analisis kimia, dapat ditarik kesimpulan bahwa perlakuan terbaik yaitu T2 untuk kadar air dan kadar abu, dan T3 untuk kandungan vitamin C.
\end{abstract}

Kata kunci: kayu manis, serai, kayu manis, teh, herbal

\section{ABSTRACT}

The use of lemongrass and cinnamon as tea is very beneficial for health. Lemongrass and cinnamon contain useful functional compounds. The objectives of this study are: 1). To determine the physicochemical content of lemongrass cinnamon herbal tea in the form of flavonoids, ash content, water content and vitamin $C$. 2). What the level of preference of panelists for lemongrass-cinnamon herbs is.

The results showed that the appropriate combination level was T2 (color, aroma) and T3 (taste). The results of the analysis of chemical properties with the addition of cinnamon are; air content $6.08 \%$ (T2), ash content 5.84\% (T2), flavonoid levels (T1), and vitamin C levels of 15.00\% (T3). The best level of panelist preference produced from 3 attributes (color, aroma, and taste) was T2 treatment (lemongrass leaves $1.5 \mathrm{~g}$ and cinnamon $0.2 \mathrm{~g}$ ). And from the data from chemical analysis, it can be concluded that the best treatment is T2 for water content and ash content, and $T 3$ for vitamin $C$ content.

Keywords: cinnamon, lemongrass, cinnamon, herbal, tea

\section{PENDAHULUAN}

Serai merupakan tanaman yang dibudidayakan di pekarangan dan sela-sela tumbuhan lain. Tanaman ini biasanya digunakan masyarakat hanya untuk kebutuhan memasak dan sebagai obatobatan. Serai dapat mengobati infeksi kulit, tipus, keracunan makanan, dan dapat juga meredakan bau badan (Wibisono, 2011).

Kayu manis selain sebagai pemberi aroma dan citarasa makanan dan minuman, juga sebagai bahan tambahan pada pembuatan parfum dan obat-obatan. Penggunaannya biasanya dilakukan dengan menambahkan langsung ke dalam makanan dan minuman, baik dalam bentuk utuh, rajangan atau dalam bentuk yang telah dihaluskan (Sundari, 2001).

Belum adanya langkah inovasi lebih lanjut dalam hal diversifikasi pangan membuat kedua tanaman ini belum banyak dilakukan penelitiaan lebih lanjut. Melalui diversifikasi produk dapat dihasilkan beraneka produk pangan makanan dan minuman yang disesuaikan dengan selara konsumen. Diversifikasi produk juga bertujuan untuk memberi nilai tambah sehingga meningkatkan harga jual yang pada akhirnya dapat memberikan pendapatan yang tinggi. Salah satunya adalah meningkatkan nilai ekonomis dari tanaman serai menjadi produk minuman sehat.

Suhu pengeringan teh yang ideal yaitu antara $60^{\circ} \mathrm{C}$ sampai $95^{\circ} \mathrm{C}$ (Wiranata, Yuwono, \& Purwantiningrum, 2016). Hal ini juga menjadi acuan bagi penelitian untuk menjaga mutu teh herbal yang dihasilkan.

Berdasarkan latar belakang dari penelitian yang akan dilakukan tersebut, maka penelitian ingin mencoba mengolah tanaman serai menjadi minuman herbal dan mengukur kandungan fisikokimia dari minuman tersebut. Teh herbal dari tanaman serai ini akan diformulasikan dengan kayu manis sebagai campurannya. Penambahan kayu manis ini bertujuan untuk pemberi rasa, aroma yang khas dan juga sebagai antimikroba dan antioksidan pada minuman. Kayu manis juga mempunyai aktivitas antioksidan dalam melawan bahaya radikal bebas (Jayanegara, Becker, \& Makkar, 2008). 


\subsection{Rumusan masalah}

Rumusan masalah dari penelitian ini adalah

1. Bagaimana kandungan fisikokimia dari teh herbal serai-kayu manis yang berupa kadar flavonoid, $\mathrm{pH}$, kadar abu, kadar vitamin C.

2. Bagaimana tingkat kesukaan panelis terhadap the herbal serai-kayu manis.

\subsection{Tujuan}

Berdasarkan latar belakang diatas, maka tujuan dari penelitian ini adalah :

1. Untuk mengetahui kandungan fisikokimia teh herbal serai-kayu manis yang berupa kadar flavonoid, kadar abu, kadar air dan kadar vitamin C.

2. Bagaimana tingkat kesukaan panelis terhadap teh herbal serai-kayu manis.

\subsection{Manfaat}

Manfaat yang diharapkan dari hasil penelitian adalah dapat menyediakan informasi mengenai mutu dari teh herbal serai-kayu manis melalui pengukuran fikikokimia dan tingkat penerimaan panelis.

\section{METODE PENELITIAN}

\subsection{Waktu dan tempat}

Penelitian ini dilakukan pada bulan AgustusSeptember 2018 di Laboratorium Teknologi Hasil Pertanian Kampus Politeknik Gorontalo.

\subsection{Alat dan bahan}

Adapun alat yang digunakan adalah: grinder, erlenmeyer, spatula, gelas ukur, oven, timbangan analitik, panci, sendok, pisau, baskom, cup plastik, kertas saring, tabung reaksi, vortex, pipet ukur, bola hisap, kuvet. Sedangkan bahan utama yang digunakan adalah tanaman sereh, kayu manis, etanol, $\mathrm{HCl}, \mathrm{Mg}$, iodin, amilum, aquades.

\subsection{Rancangan Penelitian}

Penelitian ini menggunkan Rancangan acak lengkap dengan 1 faktor, dengan perlakuan penelitian sebagai berikut:

T1: $100 \%$ serai: $0 \%$ kayu manis

T2: $75 \%$ serai: $25 \%$ kayu manis

T3: 50\% serai:50\% kayu manis

Pengujian dilakukan 3 kali pengulangan untuk analisis sifat kimia. Data yang dihasilkan kemudian diolah menggunakan analisis sidik ragam untuk melihat pengaruh perlakuan dan selanjutnya ditentukan kaidah keputusan uji lanjut BNT.

\subsection{Jenis dan Sumber Data}

Penulisan penelitian ini dilakukan dengan menelusuri pustaka dan literatur-literatur yang berhubungan yaitu berupa data primer dan data sekunder. Sember data sekunder berupa jurnal sedangkan data primer berasal dari pengujian analsis sifat kimia.

\subsection{Parameter pengamatan}

Adapun parameter yang diamati dalam kandungan fisikokimia teh herbal serai-kayu manis yang berupa kadar flavonoid, $\mathrm{pH}$, kadar abu, kadar vitamin $\mathrm{C}$ serta tingkat kesukaan panelis (uji organoleptik).

\subsection{Prosedur pembuatan teh}

Pembuatan teh serai kayu manis dimodifikasi dari metode pembuatan teh hijau (Rohdiana, 2015), sebagai berikut:

1. Menyiapkan alat dan bahan.

2. Mensortasi serai dan kayu manis.

3. Melakukan proses pengeringan.

4. Penggilingan menjadi serbuk teh.

5. Mengayak serbuk teh.

6. Menimbang serbuk teh.

7. Mengaduk hingga homogen dan dikemas dalam kantong teh.

8. Seduh dengan air panas yang mendidih kedalam gelas.

9. Teh herbal yang sudah diseduh siap untuk diminum.

10. Seduh dengan air panas yang mendidih kedalam gelas.

11. Teh herbal yang sudah diseduh siap untuk diminum.

\section{HASIL DAN PEMBAHASAN}

\subsection{Mutu Organoleptik Teh Sekam}

3.1.1. Warna

Berdasarkan uji organoleptik dari warna teh serai dari ketiga perlakuan dapat dilihat pada Gambar 1.

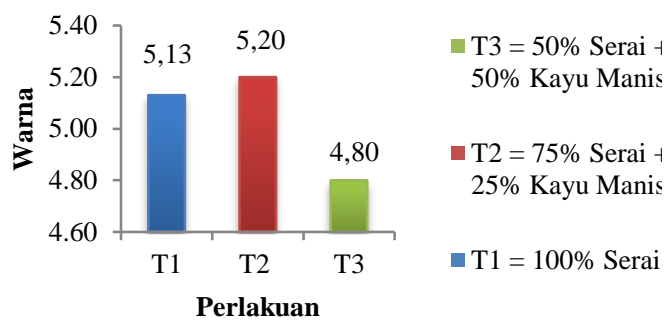

Gambar 1. Diagram tingkat kesukaan warna

Berdasarkan hasil uji organoleptik terhadap warna teh serai dengan penambahan kayu manis menunjukkan bahwa tingkat penerimaan panelis terhadap parameter warna yaitu berkisar antara 4,80 - 5,20 dalam taraf agak suka. Dari hasil pengujian tingkat kesukaan warna pada teh serai panelis berpendapat bahwa panelis lebih menyukai warna yang dihasilkan oleh perlakuan T2 dibandingkan dengan perlakuan T1 dan T3. Hal ini dikarenakan pada perlakuan T1 warna yang dihasilkan berwarna merah kecoklatan, sedangkan pada T3 warna yang dihasilkan berwarna kekuningan. Panelis lebih menyukai warna pertengahan antara $\mathrm{T} 1$ dan $\mathrm{T} 3$. Warna kecoklatan pada T1 dipengaruhi oleh kandungan katekin pada daun serai karena senyawa 
katekin merupakan salah satu terbentuknya warna pada teh yang dihasilkan (Karori, Wachira, Wanyoko, \& Ngure, 2007).

\subsubsection{Aroma}

Berdasarkan uji organoleptik dari aroma teh serai dari ketiga perlakuan dapat dilihat pada Gambar 2.

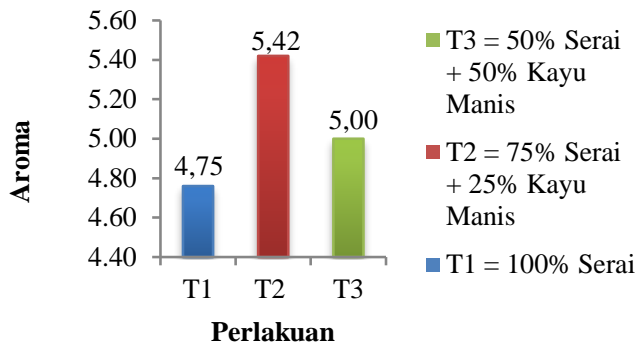

Gambar 2. Diagram tingkat kesukaan aroma

Berdasarkan hasil uji organoleptik terhadap aroma teh serai dengan penambahan kayu manis menunjukkan bahwa tingkat penerimaan panelis terhadap parameter warna pada teh serai dengan penambahan kayu manis menunjukkan nilai yang berkisar antara 4.75 - 5.42 dalam taraf agak suka. Dari hasil pengujian tingkat kesukaan aroma pada teh serai dengan penambahan kayu manis panelis berpendapat bahwa panelis menyukai aroma yang dihasilkan oleh perlakuan T2 dibandingkan dengan T1 dan T3, hal ini terjadi karena adanya kandungan sitronelal, geraniol dan sitronelol pada serai yang berfungsi untuk memberi aroma pada serai. Kandungan zat sitronellal yang merupakan cairan tak berwarna yang menghasilkan ester dan memiliki bau harum (Sastrohamidjojo, 2004). Aroma yang dihasilkan T2 lebih kuat karena adanya kombinasi antara daun dan kayu manis, gabungan dari komponen utama minyak serai tersebut juga dikenal sebagai total senyawa yang dapat diasetilasi serta dapat menentukan bau harum, nilai dan harga minyak serai (Wijesekera, 1973).

\subsubsection{Rasa}

Berdasarkan uji organoleptik dari aroma teh serai dari ketiga perlakuan dapat dilihat pada Gambar 3.

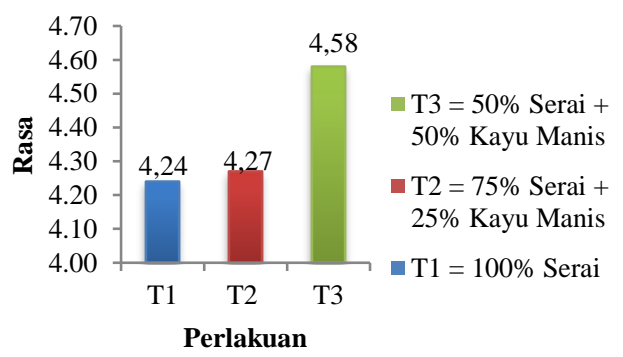

Gambar 3. Diagram tingkat kesukaan rasa

Berdasarkan hasil uji organoleptik terhadap rasa teh serai dengan penambahan kayu manis menunjukkan bahwa tingkat penerimaan panelis terhadap parameter rasa pada teh serai dengan penambahan kayu manis menunjukkan nilai yang berkisar antara 4,24 - 4.58 dalam taraf netral sampai agak suka. Dari hasil pengujian tingkat kesukaan rasa pada teh serai dengan penambahan kayu manis panelis berpendapat bahwa panelis lebih menyukai rasa yang dihasilkan oleh perlakuan T3 dibandingkan dengan perlakuan T1 dan T2, hal ini dipengaruhi oleh rasa yang dihasilkan oleh perlakuan T3 dan T2 sedikit berasa pedas dibandingkan dengan perlakuan T3.

Tanaman serai memiliki kandungan lemograss yang membuat serai memiliki aroma khas dan rasa agak pedas, kandungan lemograss atau biasa disebut minyak astri biasanya terdapat pada batang atau daun, serta kandungan kayu manis (Oyen \& Dung, 1999). Kayu manis bersifat hangat, pedas, wangi, dan sedikit manis. Rasa manis pada kayu manis ini kemungkinan berasal dari kandungan gula didalamnya.

\subsubsection{Kadar Flavonoid}

Tanin merupakan senyawa yang memiliki jumlah gugus hidroksi fenolik yang banyak pada tumbuh-tumbuhan. Tanin dapat berfungsi sebagai antioksidan karena kemampuannya dalam menstabilkan fraksi lipid dan keaktifannya dalam penghambatan lipoksigenase (Zeuthen \& BoghSorensen, 2003). Dari hasil pengujian kualitatif terhadap kandungan tanin pada teh serai dengan penambahan kayu manis menunjukan bahwa pada semua perlakuan positif mengadung tanin, karena pada serai itu sendiri mengandung tanin, adapun kandungan fitokimia dalam serai adalah alkaloid, saponin, tanin, antharaquinon, steroid, asam fenol, (Derivat Caffeicdan P-coumaric), dan flavon glikosida (derivat apigenin dan leuteolin).

\subsubsection{Kadar Air}

Hasil analisa rata-rata kadar air pada teh seraikayu manis dari tiga perlakuan ditunjukan oleh Gambar 4.

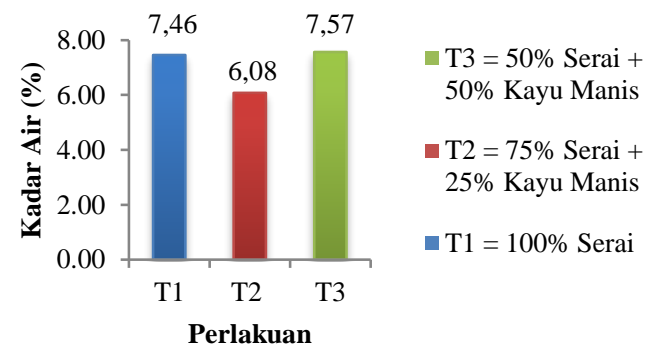

Gambar 4. Kadar air teh sekam

Berdasarkan analisis sidik ragam kadar air bahwa nilai $\mathrm{F}$ hitung (0.83) lebih kecil dari $\mathrm{F}$ tabel (5.14), analisis sidik ragam ini menunjukkan bahwa perbedaan perlakuan pada pembutan teh serai tidak berpengaruh nyata terhadap kadar air yang diperoleh. Kadar air sangat mempengaruhi daya tahan teh serai, kadar air yang tinggi akan mengakibatkan mudahnya bakteri dan jamur serta mikroba lainnya untuk 
berkembang biak sehingga akan mempengaruhi mutu dari produk tersebut. Dari Gambar 4 di atas kadar air yang tertinggi yaitu T3 dan kadar air terendah yaitu T2, hal ini di duga karena pada perlakuan T3 terdapat kayu manis. Kayu manis berasal dari bagian kulit batang sehingga karena batang merupakan salah satu organ tanaman yang fungsinya sebagai tempat mengalirnya air dari akar ke seluruh tanaman.

\subsubsection{Kadar Abu}

Hasil analisis rata-rata kadar abu pada teh serai-kayu manis dari tiga perlakuan ditunjukan oleh Tabel 1.

Tabel 1. Nilai rata-rata kadar abu

\begin{tabular}{cc}
\hline Kode Sampel & $\begin{array}{c}\text { Rata-Rata } \\
(\%)\end{array}$ \\
\hline T1 & $6.42^{\mathrm{a}}$ \\
T2 & $5.84^{\mathrm{a}}$ \\
T3 & $5.00^{\mathrm{b}}$ \\
\hline
\end{tabular}

Berdasarkan analisis sidik ragam kadar abu bahwa nilai $\mathrm{F}$ hitung $(13,32)$ lebih besar dari $\mathrm{F}$ tabel $(0,05)$ yaitu 5,14. analisis sidik ragam ini menunjukan bahwa perbedaan perlakuan pada pembutan teh serai berpengaruh nyata terhadap kadar abu yang diperoleh. Perlakuan T1 memiliki nilai kadar abu $(6.42 \%)$ yang paling tinggi dibandingkan dengan perlakuan T2 dan perlakuan T3. Abu menurut Desroiser (1988), adalah residu organik dari pembakaran bahan - bahan organik, biasanya komponen tersebut terdiri dari kalim, kalsium, natrium, besi, magan dan magnesium. Karena T1 berasal dari daun serai yang memiliki kandungan air yang tinggi, kandungan air yang tinggi akan menyebabkan kandungan mineral juga tinggi (Manvitha \& Bidya, 2014).

\subsubsection{Kadar Vitamin $C$}

Hasil analisa rata-rata kadar vitamin $\mathrm{C}$ pada teh serai-kayu manis dari tiga perlakuan ditunjukan oleh Tabel 2.

Tabel 2. Nilai rata-rata kadar vitamin C

\begin{tabular}{cc}
\hline Kode Sampel & Rata-Rata (\%) \\
\hline T1 & $5.78^{\mathrm{b}}$ \\
T2 & $13.84^{\mathrm{a}}$ \\
T3 & $15.00^{\mathrm{a}}$ \\
\hline
\end{tabular}

Berdasarkan analisis sidik ragam kadar air bahwa nilai $\mathrm{F}$ hitung (44.47) lebih $\mathrm{b}$ dari $\mathrm{F}$ tabel $(0,05)$ yaitu 5,14. Analisis sidik ragam ini menunjukan bahwa perbedaan perlakuan pada pembutan teh serai berpengaruh nyata terhadap vitamin $\mathrm{C}$ yang diperoleh. Perlakuan T3 memiliki nilai kadar vitamin $\mathrm{C}(15.03 \%)$ yang paling tinggi dibandingkan dengan perlakuan $\mathrm{T} 2$ dan perlakuan
T1. Hal ini dikarenakan perlakuan T3 memiliki kandungan fenol yang lebih tinggi yang bersumber dari kayu manis. Kebanyakan antioksidan pada pangan nabati terdiri dari fenol yan berperan pada pemecahan rantai antioksidan karena terdapat gugus $\mathrm{OH}$ yang merendam radikal bebas yang bersifat reaktif (Carlsen et al., 2010).

\section{KESIMPULAN DAN SARAN}

\subsection{Kesimpulan}

Berdasarkan hasil dan pembahasan yang telah dilakukan di atas maka diperoleh kesimpulan adalah:

1. Mutu Organoleptik yang terbaik dalam penelitian ini berada pada taraf netral sampai agak suka oleh panelis yaitu perlakuan T2 (warna, aroma) dan T3 (Rasa).

2. Berdasarkan analisis terbaik yaitu kadar air $6.08 \%$ (T2), kadar abu 5.84\% (T2) dan kadar vitamin C $15.00 \%$ (T3).

\subsection{Saran}

Setelah melakukan penelitian ini penulis menyarankan perlu adanya penetapan standar mutu teh herbal pada umumnya. Sehingga hasil uji-uji yang dilakukan dapat disesuaikan dengan standar mutu yang telah ditetapkan.

\section{DAFTAR PUSTAKA}

Carlsen, M. H., Halvorsen, B. L., Holte, K., Bøhn, S. K., Dragland, S., Sampson, L., ... Blomhoff, R. (2010). The total antioxidant content of more than 3100 foods, beverages, spices, herbs and supplements used worldwide. Nutrition Journal, 9(1). https://doi.org/10.1186/1475-2891-9-3

Jayanegara, A., Becker, K., \& Makkar, H. P. S. (2008). Methane Reduction Properties of Tannin Containing Plants, Simple Phenols and Purified Tannins in In Vitro Rumen Fermentation System. Proc. Soc. Nutr. Physiol, 17, 159.

Karori, S. M., Wachira, F. N., Wanyoko, J. K., \& Ngure, R. M. (2007). Antioxidant capacity of different types of tea products. African Journal of Biotechnology, 6(19), 2287-2296. https://doi.org/1684-5315

Manvitha, K., \& Bidya, B. (2014). Review on pharmacological activity of Cymbopogon citratus. International Journal of Herbal Medicine, 1(6), 5-7.

Oyen, L. P. A., \& Dung, N. X. (Eds.). (1999). Essential-Oil Plants. Plant Resources of South East Asia No 19. Leiden: Backhuys Publishers.

Rohdiana, D. (2015). Teh: Proses, Karakteristik \& Komponen Fungsionalnya. Food Review Indonesia, 10(8), 34-37.

Sastrohamidjojo, H. (2004). Kimia Minyak Atsiri. 
Yogyakarta: UGM Press.

Sundari, E. (2001). Pengambilan minyak atsiri dan oleoresin dari kulit kayu manis. Institut Teknologi Bandung.

Wibisono, W. G. (2011). Tanaman Obat Keluarga Berkhasiat. Ungaran: Vivo Publisher.

Wijesekera, R. O. B. (1973). Chemical Composition and Analysis. Journal of National Science Council of Srinlanka, 1, 67-81.

Wiranata, G., Yuwono, S. S., \& Purwantiningrum, I. (2016). Pengaruh Lama Pelayuan Dan Suhu Pengeringan Terhadap Kualitas Produk Apel Celup Anna (Malus domestica). Jurnal Pangan Dan Agroindustri, 4(1), 449-457.

Zeuthen, P., \& Bogh-Sorensen, L. (2003). Food preservation techniques. Cambridge: CRC Press. 